\title{
Evaluation of natural support capacity of water resources using principal component analysis method: a case study of Fuyang district, China
}

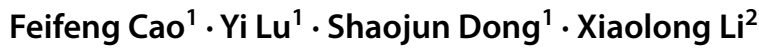

Received: 13 May 2019 / Accepted: 3 March 2020 / Published online: 13 July 2020

(c) The Author(s) 2020

\begin{abstract}
The natural support capacity (NSC) of water resources is a key aspect of the regional carrying capacity of water resources, and it can reflect the quality and quantity of water resources in a region. This paper aims to evaluate the NSC of water resources using a model based on the principal component analysis (PCA) to benefit the development and utilization of regional water resources. A case study in the Fuyang district, Zhejiang Province, China, was carried out. First, water resources, as dependent variables, were assumed to be linearly influenced by the indicators affecting the NSC of water resources. These indicators were regarded as independent variables for multivariate analysis in this study. Then, the available water resources data for the Fuyang district between 1995 and 2003 were inputted to the model to analyze NSC levels of water resources. The results indicated that the most important parameters influencing the NSC of water resources could be shortlisted to water resources availability, surface water resources, groundwater resources, allowable withdrawal of water resources, and emission intensity of chemical oxygen demanding. Our findings revealed that the NSC of water resources in the Fuyang district fluctuated between 1995 and 1999 and generally declined after 2000, indicating that the issue of water pollution has worsened since 2000. These results are consistent with the field observations and thus shall provide new potential applications of a PCAbased model in evaluating the NSC of water resources and the relevant water resource carrying capacity for similar areas.
\end{abstract}

Keywords Water resource · Natural support capacity · Carrying capacity of water resources · Principal component analysis

\section{Introduction}

Human demand for water resources is continually increasing as a result of the continuous advancement of science and technology, the rapid development of social economy, and the improvement of people's living standards, particularly

Feifeng Cao

cff@zjut.edu.cn

Yi Lu

luyi0123@qq.com

Shaojun Dong

DDDSJYY@163.com

Xiaolong Li

624972641@qq.com

1 College of Civil Engineering and Architecture, Zhejiang University of Technology, Hangzhou 310014, China

2 Hangzhou Yongji Water Science and Technology Co. Ltd, Hangzhou 310000, China in developing countries such as China (Shang et al. 2016). Food and Agriculture Organization of the United Nations (2016) reported that $67 \%$ of the world's population could be living with water stress and 1.8 billion people could be living in countries or regions with absolute water scarcity by 2025 . In addition, there are other water issues like water pollution that could also seriously influence people's living environment. Thus, analysis and evaluation of current regional water resources are important first steps to manage these problems.

Water resource carrying capacity (WRCC) is a common term used to analyze and evaluate the state of water resources of a certain region. In previous studies, a universal definition of WRCC has not been reached. For example, in a study by Zhu et al. (2002), WRCC was defined as the threshold of water resources with which the environment can provide to sustain human activities. Shi et al. argued that WRCC reflected the maximum population that water resources could support in a region (Shi and Qu 1992). Clarke (2002) and Khanna et al. (1999) maintained that WRCC was a concept 
that focused on sustainable socioeconomic development in a region or basin. Although several WRCC definitions exist, they were defined by different research goals. The definition of WRCC that is most agreed upon by researchers is that WRCC reflects both natural attributes and availability of water resources as well as economic development in society. Thus, an indicator called the natural support capacity (NSC) of water resources is defined in the present research, which comprehensively reflects the natural attributes of water in terms of the state of quality and quantity of water resources in a region. The evaluation result of NSC is then used to reflect water quality and quantity in a region.

At present, the comprehensive evaluation methods of WRCC primarily include index evaluation method (Xu 1993), fuzzy comprehensive evaluation method (Tao et al. 2011; Li and Jin 2009), system dynamics method (Wu and Zeng 2003; Zhai et al. 2009), and the principal component analysis (PCA) method (Zhang et al. 2011; Fu and Ji 1999; Tripathi and Singal 2019). Both the index evaluation method and the fuzzy comprehensive evaluation method are comprehensive ones to provide a complete picture of the water resource situation; however, one main shortcoming of these methods is the high level of evaluation subjectivity that could cause the loss of relevant information and thus the decrease of evaluation accuracy, particularly when there are a number of influencing factors for analysis. In terms of the system dynamics method that combines the society, economy, resources, and environment factors into a complex dynamic system, it can be used to reveal the hidden information that often underlies the complex data set through a realtime dynamic operation. While this data analysis method has been mostly applied to analyze WRCC over a short period, when estimating WRCC over a longer period, such as several years, unreasonable analysis results could be obtained, given that relative variables are difficult to determine. As a standard tool in modern data analysis for diverse fields from computer graphics (Yuan and Zheng 2018) to neuroscience (Haid et al. 2018), the PCA method reduces the dimension of the variable system and thus the number of parameters by linearly transforming the original variables and extracting useful information from confusing data sets. This method can determine the weight of all variables objectively and avoid the high level of subjectivity that occurs in the fuzzy comprehensive judgment method.

Regarding the application of PCA in WRCC, the PCA method has been mainly applied in assessing the regional water quality (Zhang et al. 2011; Tripathi and Singal 2019; Zeinalzadeh and Rezaei 2017; Gorde and Jadhav 2013), while little research was found in evaluating both water quality and quantity in a region. For example, Tripathi and Singal (2019) conducted a parameter selection for using PCA in evaluating water quality in the Ganga River in India. The relevant number of parameters was reduced from 28 to 9 parameters, including parameters such as dissolved oxygen and $\mathrm{pH}$. These parameters are useful to form the basis of development of a Ganga Water Quality Index in the future.

This paper focuses on the application of the PCA method in the NSC of water resources to evaluate NSC that reflects both the quality and quantity of regional water resources. Based on the collected hydrologic statistics of the Fuyang district, the PCA method was applied to analyze all influencing parameters of the NSC of water resources; the most important parameters were then selected. The NSC level of water resources in the Fuyang district from 1995 to 2003 was finally calculated by using the weighted-average values of the principal components. The research results can be potentially used to analyze the development and utilization of regional water resources in the Fuyang district and provide references to evaluate the NSC of water resources in similar cities or regions.

\section{Methods}

\section{The PCA method}

Many variables can reflect characteristics of the water resources for the multi-attribute decision-making problem of water resources. Among these variables, there are several dominant ones. In order to reduce excessive calculation and the calculation complexity caused by too many dependent variables but still retaining maximum variance, these dominant variables can be first selected to perform quantitative analysis (Tripathi and Singal 2019).

The PCA method is an effective way to analyze the multiattribute decision-making problem. It can calculate several comprehensive indicators, usually called principal components, by studying the internal structure relationship of the original variable correlation matrix. The principal components not only retain the main information of the original variables but also have superior properties to the original variables, which makes it easy to solve the original problem. The main process of the PCA method is as follows.

We assume that there are $p$ indicators, and each of them has $n$ samples. The original data can be expressed as

$X=\left[\begin{array}{cccc}x_{11} & x_{12} & \cdots & x_{1 p} \\ x_{21} & x_{22} & \cdots & x_{2 p} \\ \vdots & \vdots & \vdots & \vdots \\ x_{n 1} & x_{n 2} & \cdots & x_{n p}\end{array}\right]$

where $x_{i j}=$ original variables.

First, the original variables of matrix $X$ are standardized to produce matrix $C$ with the standard score method. It can be stated as 
$C_{i j}=\left(x_{i j}-\bar{x}_{j}\right) / S_{j}$

$\bar{x}_{j}=\sum_{i=1}^{n} x_{i j} / n$

$S_{j}^{2}=\sum_{1}^{n}\left(x_{i j}-\bar{x}_{j}\right)^{2} /(n-1)$

where $i=1,2, \ldots, n ; j=1,2, \ldots, p$.

Second, the correlation coefficient matrix of $C$ is calculated and represented as

$R=\left[\begin{array}{cccc}r_{11} & r_{12} & \cdots & r_{1 p} \\ r_{21} & r_{22} & \cdots & r_{2 p} \\ \vdots & \vdots & \vdots & \vdots \\ r_{p 1} & r_{p 2} & \cdots & r_{p p}\end{array}\right]$

where $r_{j k}$ represents the correlation coefficient of $x_{i j}$ and $x_{i k}$.

Third, the eigenvalues and eigenvectors of the correlation matrix $R$ are calculated to determine the principal component. The eigenvalues are ranked as $\lambda_{1} \gg \lambda_{2} \gg \cdots \gg \lambda_{i} \gg 0$, and the corresponding unit eigenvectors can be written as $\alpha_{i}=\left(\alpha_{1 i}, \alpha_{2 i}, \ldots, \alpha_{p i}\right)$, in which $i=1,2, \ldots, p$. The principal component $F_{i}$ can be thus written as

$F_{i}=\alpha_{1 i} C_{1 i}+\alpha_{2 i} C_{2 i}+\ldots+\alpha_{p i} C_{p i}$

where $F_{i}$ represents the $i$ th principal component. For example, $F_{1}$ represents the first principal component; $F_{2}$ represents the second principal component; and $F_{3}$ represents the third principal component, and so on.

Then, the cumulative variance contribution rate is calculated to determine the number of principal components. In general, the number of principal components is equal to that of the original indicators. However, if there are excessive original indicators, the complexity of calculation and comprehensive evaluation would greatly increase. Therefore, fewer principal components should be selected. The number of principal components, $k$, can be determined by the cumulative variance contribution rate, which can be stated as

$E=\left(\sum_{i}^{k} \lambda_{i}\right) /\left(\sum_{i}^{p} \lambda_{i}\right) \gg 80 \%$

Finally, the comprehensive evaluation value, $F$, is calculated as

$F=\sum_{i=1}^{k} e_{i} F_{i}$

where $e_{i}$ represents the variance contribution rate of each principal component and can be given as $e_{i}=\lambda_{i} / \sum_{i=1}^{p} \lambda_{i}$

\section{Hydrologic statistics and water resource conditions in the Fuyang district}

Fuyang district, the administrative area of which is $1831 \mathrm{~km}^{2}$, is in the northwest of Zhejiang Province in China. The Fuchun River is the primary stream of the Qiantang River, running through the central part of Fuyang. Qiantang River is an important river in East China. It runs for $459 \mathrm{~km}$ through Zhejiang province, passing through the provincial capital Hangzhou before flowing into the East China Sea via Hangzhou Bay. The Fuchun River is the primary stream of the Qiantang River, running through the central part of Fuyang district. As the primary water source in the Fuyang district, the Fuchun River has a catchment area of $2486.5 \mathrm{~km}^{2}$.

In accordance with the rapid development of the economy in Fuyang, the rapid increase in population, and the continuous improvement of living standards, water consumption and sewage discharge are increasing. Most of the industrial wastewater and domestic sewage are directly discharged into the Fuchun River without effective treatments, especially the sewage generated by the paper industry, posing a threat to the water environment along the coast. The local residents are complaining about water pollution.

The average annual precipitation in Fuyang is $27.2 \times 10^{8} \mathrm{~m}^{3}$. The average amount of annual surface water resources is $13.8 \times 10^{8} \mathrm{~m}^{3}$, and the amount of groundwater resources is $3.2 \times 10^{8} \mathrm{~m}^{3}$. The amount of total available surface water resources is $8.2 \times 10^{8} \mathrm{~m}^{3}$, which is 0.583 times that of the average surface water resource availability in the past 10 years.

The amount of water supply has an increasing trend in recent years. The average water supply in Fuyang from 1998 to 2003 was $4.36 \times 10^{8} \mathrm{~m}^{3}$. The groundwater is $0.31 \times 10^{8} \mathrm{~m}^{3}$, accounting for $7.07 \%$ of the total water supply; the surface water was $4.05 \times 10^{8} \mathrm{~m}^{3}$, accounting for $92.93 \%$ of the total water supply. The average water consumption and average water dissipation were $4.36 \times 10^{8} \mathrm{~m}^{3}$ and $1.82 \times 10^{8} \mathrm{~m}^{3}$, respectively. Table 1 provides detailed data about water usage in different fields.

\section{Indicator system for NSC evaluation of water resources}

According to the available data of water resources in Fuyang district, an indicator system with two types of indicators (a total of eight water quality and water quantity indicators) was established for the NSC evaluation of regional water resources (Table 2). The first type of indicator is the water

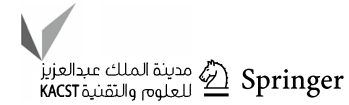


Table 1 Average values of water usage in the Fuyang district (ZWRD 1998-2003)
Table 2 Values of NSC indicator of the Fuyang district between 1995 and 2003 (HEEB 1995-2003)

\begin{tabular}{llcll}
\hline Water usage & $\begin{array}{l}\text { Agricultural } \\
\text { water } / 10^{4} \mathrm{~m}^{3}\end{array}$ & $\begin{array}{l}\text { Industrial } \\
\text { water } / 10^{4} \mathrm{~m}^{3}\end{array}$ & $\begin{array}{l}\text { Urban domestic } \\
\text { water } / 10^{4} \mathrm{~m}^{3}\end{array}$ & $\begin{array}{l}\text { Uural } \\
\text { domestic } \\
\text { water } / 10^{4} \mathrm{~m}^{3}\end{array}$ \\
\hline Water consumption & 18,100 & 23,200 & 900 & 1500 \\
Water dissipation & 11,800 & 4900 & 200 & 1300 \\
\hline
\end{tabular}

\begin{tabular}{lrrrrrrrr}
\hline Year & $C 1 / 10^{4} \mathrm{~m}^{3}$ & $C 2 / 10^{4} \mathrm{~m}^{3}$ & $C 3 / 10^{4} \mathrm{~m}^{3}$ & $C 4 / 10^{4} \mathrm{~m}^{3}$ & $C 5 / \%$ & $C 6 / 10^{4} \mathrm{~m}^{3}$ & $C 7 / \%$ & $\begin{array}{l}C 8 / \\
\left(\mathrm{kg} / 10^{4}\right. \\
\mathrm{RMB})\end{array}$ \\
\hline 1995 & $156,580.20$ & $33,607.15$ & $135,398.42$ & $85,056.67$ & 95.65 & 644.262 & 2.322 & 32.0 \\
1996 & $161,101.60$ & $39,679.90$ & $145,992.57$ & $92,095.88$ & 95.65 & 650.060 & 2.297 & 29.1 \\
1997 & $148,632.20$ & $28,866.55$ & $122,709.83$ & $66,775.40$ & 95.65 & 662.411 & 2.250 & 27.1 \\
1998 & $159,170.00$ & $35,231.03$ & $139,612.10$ & $79,817.29$ & 95.65 & 678.971 & 2.176 & 25.9 \\
1999 & $161,935.30$ & $41,736.36$ & $178,882.73$ & $86,887.92$ & 90.91 & 702.056 & 1.929 & 23.7 \\
2000 & $98,265.30$ & $24,823.63$ & $68,299.99$ & 3705.19 & 90.91 & 730.139 & 1.830 & 21.3 \\
2001 & $137,876.20$ & $30,943.13$ & $104,030.42$ & $46,835.61$ & 90.91 & 762.995 & 1.834 & 19.7 \\
2002 & $136,357.00$ & $29,998.54$ & $111,566.61$ & $30,271.80$ & 90.91 & 801.145 & 1.166 & 15.4 \\
2003 & $115,540.00$ & $27,559.00$ & $89,310.07$ & 840.26 & 84.36 & 843.605 & 1.112 & 10.6 \\
\hline
\end{tabular}

quantity indicator, including surface water resources $(C 1)$, groundwater resources $(C 2)$, water resources availability $(C 3)$, and allowable withdrawal of water resources $(C 4)$. The other type is the water quality indicator, including pass rate of water environmental capacity $(C 5)$, ecological water requirement (C6), ratio of ecological water requirement and available water resources $(C 7)$, and emission intensity of chemical oxygen demand $(C 8)$. The available values of these indicators from 1995 to 2003 in the Fuyang district are presented in Table 2. It should be noted that the indicator values after 2003 have neither not been measured by Fuyang's administration government nor not disclosed to the public.

It should also be noted that the water resources availability indicator $(C 3)$ reflects the maximum amount of water that can be used at one time. It considers the economy and technique levels in a certain period and the water supply conditions for the daily lives of people, industry activities, and eco-environmental demand. The water resources availability can be given as

$Q_{1}=Q_{2}+Q_{3}-Q_{4}-Q_{5}$

where $Q_{1}$ represents the water resources availability; $Q_{2}$ indicates the surface water resources availability; $Q_{3}$ represents the groundwater resources availability; $Q_{4}$ refers to the repeated part between $Q_{2}$ and $Q_{3}$; and $Q_{5}$ refers to the ecological water requirement.

The ecological water requirement (C6) includes the in-stream ecological water requirement and out-stream ecological water requirement. The in-stream ecological water requirement can be calculated using two methods according to the Second National Water Assessment in the USA (1978). When the river runoff is measured at a frequency of $70 \%$ in the data series, generally over a period of 20 years, it can ensure that most aquatic organisms have essential habitat conditions. If measured at a frequency of $90 \%$ in the data series, the river runoff can satisfy the living condition requirement of most aquatic organisms for a short time. However, if runoff is measured at less than the above runoff for an extended period, it may lead to the extinction of species and destruction of the ecological environment. In the research presented in this paper, the first method was applied to calculate the in-stream ecological water requirement. In order to meet the requirement of high accuracy, the in-stream ecological water requirement should be calculated month by month and then accumulated to attain the annual values. The annual in-stream ecological water requirement can be expressed as

$Q_{\text {in }}=\sum_{i=1}^{12}\left(q_{i} \times T_{i} \times 86,400\right)$

where $Q_{\text {in }}$ represents the annual in-stream ecological water requirement; $q_{i}$ indicates the average monthly river runoff at a frequency of $70 \%$ in the $i$ month; and $T_{i}$ represents the number of days in the $i$ th month.

The out-stream ecological water requirement can be calculated directly by

$Q_{\text {out }}=\sum A_{i} \times r_{i}$ 
Table 3 Correlation coefficient matrix of NSC

\begin{tabular}{lllllllll}
\hline & $C 1$ & $C 2$ & $C 3$ & $C 4$ & $C 5$ & $C 6$ & $C 7$ & $C 8$ \\
\hline$C 1$ & 1 & 0.849 & 0.926 & 0.959 & 0.663 & -0.655 & 0.604 & 0.658 \\
$C 2$ & 0.849 & 1 & 0.939 & 0.843 & 0.396 & -0.511 & 0.457 & 0.499 \\
$C 3$ & 0.926 & 0.939 & 1 & 0.897 & 0.480 & -0.575 & 0.496 & 0.556 \\
$C 4$ & 0.959 & 0.843 & 0.897 & 1 & 0.779 & -0.826 & 0.788 & 0.828 \\
$C 5$ & 0.663 & 0.396 & 0.480 & 0.779 & 1 & -0.915 & 0.875 & 0.915 \\
$C 6$ & -0.655 & -0.511 & -0.575 & -0.826 & -0.915 & 1 & -0.970 & -0.989 \\
$C 7$ & 0.604 & 0.457 & 0.496 & 0.788 & 0.875 & -0.970 & 1 & 0.963 \\
$C 8$ & 0.658 & 0.499 & 0.556 & 0.828 & 0.915 & -0.989 & 0.963 & 1 \\
\hline
\end{tabular}

Table 4 Eigenvalues and contribution rate of variance

\begin{tabular}{lll}
\hline Number & $\lambda_{i}$ & $E / \%$ \\
\hline 1 & 6.23 & 77.87 \\
2 & 1.42 & 95.60 \\
\hline
\end{tabular}

where $Q_{\text {out }}$ represents the annual out-stream ecological water requirement; $A_{i}$ represents the area of vegetation coverage; and $r_{i}$ indicates the ecological water requirement for vegetation coverage per unit area.

The ecological water requirement (6) can be expressed as

$Q_{5}=Q_{\text {in }}+Q_{\text {out }}$

\section{Results}

\section{Principal component analysis}

According to the PCA method, the correlation coefficient matrix of NSC was calculated by Eqs. (1)-(5) based on Table 2. The calculation results of the correlation coefficient matrix are presented in Table 3.

The eigenvalues, $\lambda_{i}$, of the correlation coefficient matrix in Table 3 were then calculated. Subsequently, the cumulative variance contribution rate, $E$, was calculated using Eq. (7) based on the eigenvalues. The calculation results of eigenvalues and the cumulative variance contribution rate are given in Table 4. The corresponding unit eigenvectors are given in Table 5.

Based on Eq. (7), the number of principal components was determined. When the number was 2, $E=95.6 \%>80 \%$. Therefore, there were only two principal components:

$$
\begin{aligned}
F_{1}= & 0.143 C 1+0.124 C 2+0.132 C 3+0.157 C 4 \\
& +0.138 C 5-0.148 C 6+0.141 C 7+0.147 C 8
\end{aligned}
$$

and

$$
\begin{aligned}
F_{2}= & 0.261 C 1+0.412 C 2+0.382 C 3+0.124 C 4 \\
& -0.287 C 5+0.258 C 6-0.296 C 7-0.264 C 8
\end{aligned}
$$

Table 5 Unit eigenvectors

\begin{tabular}{lrr}
\hline Index & \multicolumn{2}{c}{ Eigenvector } \\
\cline { 2 - 3 } & \multicolumn{1}{c}{$\lambda_{1}$} & \multicolumn{1}{l}{$\lambda_{2}$} \\
\hline$C 1$ & 0.143 & 0.261 \\
$C 2$ & 0.124 & 0.412 \\
$C 3$ & 0.132 & 0.382 \\
$C 4$ & 0.157 & 0.124 \\
$C 5$ & 0.138 & -0.287 \\
$C 6$ & -0.148 & 0.258 \\
$C 7$ & 0.141 & -0.296 \\
$C 8$ & 0.147 & -0.264 \\
\hline
\end{tabular}

Table 6 Variance contribution rate of each principal component

\begin{tabular}{lll}
\hline Number & $\begin{array}{l}\text { Principal } \\
\text { components }\end{array}$ & $e_{i}$ \\
\hline 1 & $F_{1}$ & 81.44 \\
2 & $F_{2}$ & 18.56 \\
\hline
\end{tabular}

The variance contribution rate of each principal component, $e_{i}$, was calculated using Eq. (9), and the results are given in Table 6.

Based on Eq. (8), the evaluation value of the NSC of water resources can be summed from Eqs. (14) and (15) as

$$
\begin{aligned}
F= & 0.158 C 1+0.169 C 2+0.171 C 3+0.144 C 4 \\
& +0.057 C 5-0.069 C 6+0.057 C 7+0.068 C 8
\end{aligned}
$$

According to the above composition components of $F$, the contribution ranking is $0.171(C 3)>0.169$ $(C 2)>0.158(C 1)>0.144(C 4)>0.068(C 8)>0.057(C 5$ and $C 7)>-0.069(C 6)$. Thus, the most important influencing factors on the NSC of water resources are $C 3$ (water resources availability), $C 2$ (groundwater resources), $C 1$ (surface water resources), $C 4$ (allowable withdrawal of water resources), and $C 8$ (emission intensity of chemical oxygen demanding). Although the contribution values of $C 5, C 6$, and $C 7$ are minimal, they are still used to calculate 
the NSC in this study ("NSC levels of water resources" section). Note that the extra calculation cost for these three indicators is negligible.

\section{NSC levels of water resources}

The evaluation values of the NSC of water resources in the Fuyang district between 1995 and 2003 were finally calculated using Eq. (16). Figure 1 presents the $F$ values at different years from 1995 to 2003 . It can be observed that in the years between 1995 and 1999, the $F$ values fluctuate between 0 and 1 with first increase then decrease and increase. Beginning in 2000, the $F$ values significantly drop to below -1.0 and then fluctuate. It can also be observed that the higher the value of $F$, the higher the level of NSC. Thus, the Fuyang district generally experienced a decline in the NSC level after the year 2000, although some fluctuations are observed.

\section{Discussion}

The present study shows that the NSC levels declined in Fuyang district beginning in the year 2000. The reason behind this result can be explored in terms of water quantity variation and the amount of water pollution in Fuyang.

According to the United Nations Department of Economic and Social Affairs (2005), an area can be defined as the water-rich place where the annual water supplies are more than $1700 \mathrm{~m}^{3}$ per person. The Fuyang district qualifies as a humid region in China given that its water

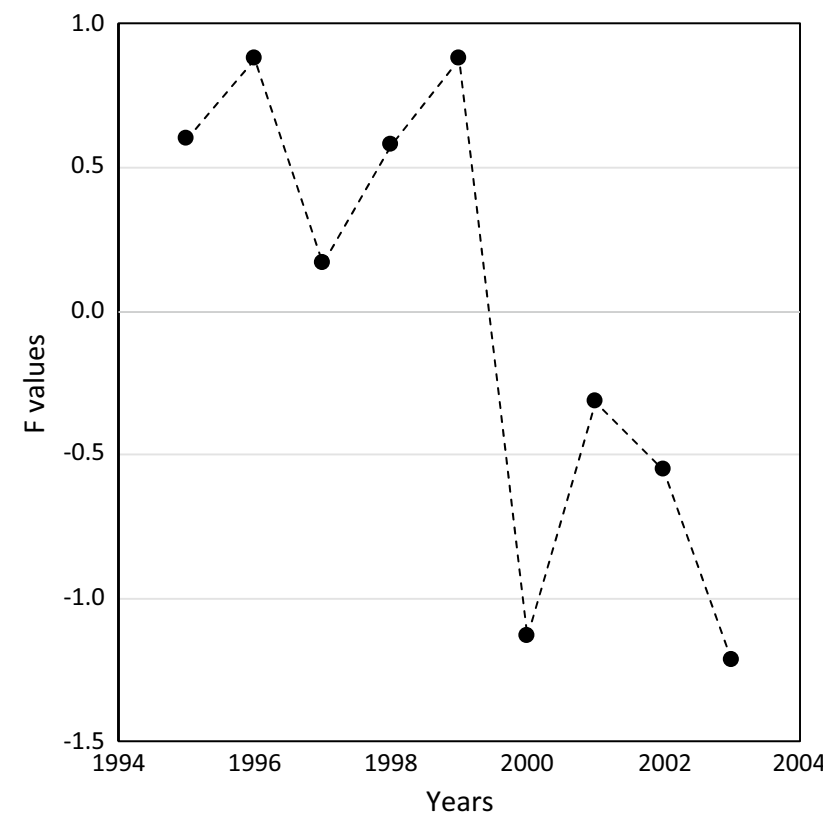

Fig. 1 Evaluation values of NSC in the Fuyang district between 1995 and 2003 using $F$ values supplies are greater than $2000 \mathrm{~m}^{3}$ per person. In addition, the natural water supplies are shown to be stable throughout the observation period of this study; thus, the quantity of water would not cause the decline of NSC levels of water resources in this region.

On the other hand, paper industries in the Fuyang district increased significantly from 1999 to 2003, causing a sharp increase in water consumption and sewage discharge (HEEB 1995-2003). Although environmental protection policies were implemented in Fuyang, the fast-paced economic development continued to cause water pollution problems, inducing a vulnerable water resources environment and decreasing natural supply support capacity. As natural water supplies in Fuyang district were stable from 1999 to 2003, it is the water pollution, rather than water scarcity, that mainly caused the decline of the NSC in the Fuyang district between 1995 and 2003.

A number of methods can be taken, considering the most influential parameters, to improve the NSC level of water resources and thus the WRCC in Fuyang district. To begin with, saving water is a critical way to improve the NSC level as the most important factor is the water resources availability. Saving water can not only improve the water resources availability but also contribute to the harmonious development of social economy and environmental protection. In addition, improving sewage treatment efficiency could also be helpful to increase NSC levels. Sewage discharge leads to an increase in chemical oxygen demand concentration and thus emission intensity of chemical oxygen, which is an important factor of NSC. It has been reported that, in most rivers, with the exception of the Fuchun River in the Fuyang district, varying degrees of water pollution caused by sewage discharge have been observed. For instance, the water quality of the Huangtian River is poor, mainly due to the abundance of production sewage, domestic sewage, and garbage being poured into the river, especially in the dry season. One method to improve the efficiency of sewage treatment and sewage recycling is to develop environmental protection industries and cleaner production technologies.

Furthermore, improving the management model of water resources can also benefit the local NSC of water. Many international practices have shown that the integration of water management is an ideal model to stimulate the overall benefits of water resources. The key to achieving integration of water management is the establishment of an authoritative department of water management that manages the quantity of water, the quality of water, and the water source, and carries out flood protection, water supply, drainage, and sewage treatment and recycling.

The successful application of PCA in evaluating the NSC of water resources in the Fuyang district, China, can provide potential applications of a PCA-based model in 
evaluating the NSC of water resources in similar areas. Further research can be performed to compare the NSC with other WRCC-relevant indexes, such as Water Quality Index (Zeinalzadeh and Rezaei 2017), to provide an optimum approach to evaluate the water resource carrying capacity.

\section{Conclusions}

This research applied the principal component analysis (PCA) method to analyze and evaluate the natural support capacity (NSC) level of water resources in the Fuyang district between 1995 and 2003. The eight parameters relevant to NSC, including surface water resources $(C 1)$, groundwater resources $(C 2)$, water resources availability $(C 3)$, allowable withdrawal of water resources $(C 4)$, pass rate of water environmental capacity (C5), ecological water requirement $(C 6)$, ratio of ecological water requirement and available water resources (C7), and emission intensity of chemical oxygen demand $(C 8)$, were analyzed, and the dominant parameters were selected. The following conclusions can be made:

- PCA results indicate that the most important influencing factors on the NSC in the Fuyang district are water resources availability, groundwater resources, surface water resources, allowable withdrawal of water resources, and emission intensity of chemical oxygen demand.

- An insignificant variation of NSC in the Fuyang district between 1995 and 1999 was found, while there was a significant decline trend of NSC after 2000. This is because water pollution became severe due to excessive sewage discharge into rivers in the Fuyang district.

- The PCA method is capable of selecting dominant variables from many dependent variables, and it can be potentially applied for analyzing and evaluating the NCR level of water resources in other regions similar to the Fuyang district.

- It is helpful to increase the NSC of water resources in the Fuyang district by taking measures such as saving water quantity, improving sewage treatment efficiency, and improving the management model of water resources.

Funding This study was supported by the funding from the Zhejiang Provincial Natural Science Foundation (LY04E090007); Zhejiang Province Science and Technology Plan (2013C33006).

\section{Compliance with ethical standards}

Conflict of interest The authors declare that they have no conflict of interest.

Open Access This article is licensed under a Creative Commons Attribution 4.0 International License, which permits use, sharing, adaptation, distribution and reproduction in any medium or format, as long as you give appropriate credit to the original author(s) and the source, provide a link to the Creative Commons licence, and indicate if changes were made. The images or other third party material in this article are included in the article's Creative Commons licence, unless indicated otherwise in a credit line to the material. If material is not included in the article's Creative Commons licence and your intended use is not permitted by statutory regulation or exceeds the permitted use, you will need to obtain permission directly from the copyright holder. To view a copy of this licence, visit http://creativecommons.org/licenses/by/4.0/.

\section{References}

Clarke AL (2002) Assessing the carrying capacity of the Florida Keys. Popul Environ 23:405-418. https://doi.org/10.1023/A:10145 76803251

Food and Agricultural Organization (2016) Coping with water scarcity: challenge of the twenty-first century. https://ideas.repec.org/p/ess/ wpaper/id11330.html. Accessed 22 Feb 2019

Fu X, Ji CM (1999) A comprehensive evaluation of the regional water resource carrying capacity: application of main component analysis method. Resourc Environ Yangtze Basin 8:168-173 (in Chinese)

Gorde SP, Jadhav MV (2013) Assessment of water quality parameters: a review. Int J Eng Res Appl 3:2029-2035

Haid TH, Doix ACM, Nigg BM, Federolf PA (2018) Age effects in postural control analyzed via a principal component analysis of kinematic data and interpreted in relation to predictions of the optimal feedback control theory. Front Aging Neurosci 10:22. https://doi.org/10.3389/fnagi.2018.00022

Hangzhou Ecological Environment Bureau (HEEB), China (2003) Bulletin of environmental status of Fuyang city in 1995-2003, Hangzhou (in Chinese)

Khanna P, Babu PR, George MS (1999) Carrying-capacity as a basis for sustainable development: a case study of National Capital Region in India. Prog Plan 52:101-166. https://doi.org/10.1016/ S0305-9006(99)00004-5

Li G, Jin C (2009) Fuzzy comprehensive evaluation for carrying capacity of regional water resources. Water Resour Manag 23:25052513. https://doi.org/10.1007/s11269-008-9393-y

Shang YZ, You B, Shang L (2016) China's environmental strategy towards reducing deep groundwater exploitation. Environ Earth Sci 75:1439. https://doi.org/10.1007/s12665-016-6110-7

Shi YF, Qu YG (1992) The water resources carrying capacity and rational utilization of Urumqi River Basin. Science Press, Beijing

Tao W, Yang MZ, Li YJ (2011) Assessment of groundwater specific vulnerability in Guangzhou base on the fuzzy comprehensive evaluation. Int Symp Water Resour Environ Prot. https://doi. org/10.1109/ISWREP.2011.5892967

Tripathi M, Singal SK (2019) Use of principal component analysis for parameter selection for development of a novel water quality index: a case study of river Ganga India. Ecol Indic 96:430-436. https://doi.org/10.1016/j.ecolind.2018.09.025

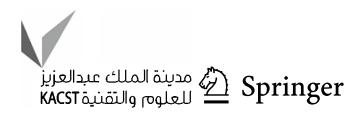


United Nations Department of Economic and Social Affairs (20052015) International decade for action 'Water for Life'. http://www. un.org/waterforlifedecade/scarcity.shtml. Accessed 27 Jan 2019

Water Resources Council (U.S.) (1978-1979) The Nation's water resources, 1975-2000: second national water assessment. https ://water.usgs.gov/watercensus//file/Vol_4_Pacific_NW.pdf. Accessed 10 March 2019

Wu JH, Zeng KH (2003) System dynamics study on urban water resources carrying capacity. J Econ Water Resour 3:36-39 (In Chinese)

Xu YP (1993) A study of comprehensive evaluation of the water resource carrying capacity in the arid area: a case study in the Hetian river basin of Xinjiang. J Nat Resour 8:229-237 (in Chinese)

Yuan H, Zheng C (2018) Adaptive rendering based on robust principal component analysis. Vis Comput 34:551-562. https://doi. org/10.1007/s00371-017-1360-2

Zeinalzadeh K, Rezaei E (2017) Determining spatial and temporal changes of surface water quality using principal component analysis. J Hydrol Reg Stud 13:1-10. https://doi.org/10.1016/j. ejrh.2017.07.002
Zhai C, Zhang HW, Zhang X (2009) Application of system dynamics in the forecasting water resources demand in Tianjin Polytechnic University. Int Conf Artif Intell Comput Intell. https://doi. org/10.1109/AICI.2009.272

Zhang XD, Wu JH, Song B (2011) Application of principal component analysis in groundwater quality assessment. Int Symp Water Resour Environ Prot. https://doi.org/10.1109/ISWRE P.2011.5893671

Zhejiang Water Resources Department (ZWRD), China (2003) Zhejiang water resources bulletins (1998-2003), Hangzhou (in Chinese)

Zhu YZ, Xia J, Tan G (2002) A primary study on the theories and process of water resources carrying capacity. Prog Geogr 21:180-188 (in Chinese)

Publisher's Note Springer Nature remains neutral with regard to jurisdictional claims in published maps and institutional affiliations. 